\title{
A step forward or running from risk?
}

\author{
Jean Bismuth, MD, and Michael J. Reardon, MD
}

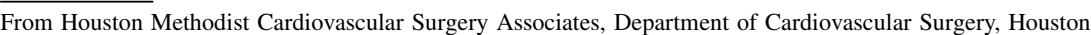
Methodist Hospital, Houston, Tex.

Disclosures: M.J.R. is national primary investigator for the Gore type A stent graft EFS. J.B. has nothing to disclose with regard to commercial support.

Received for publication Nov 9, 2017; accepted for publication Nov 13, 2017; available ahead of print Dec 14, 2017.

Address for reprints: Michael J. Reardon, MD, Allison Family Distinguished Chair of Cardiovascular Research, Houston Methodist Hospital, Smith Tower, 6550 Fannin St, Suite 1401, Houston, TX 77030 (E-mail: mreardon@houstonmethodist.org).

J Thorac Cardiovasc Surg 2018;155:905-6

$0022-5223 / \$ 36.00$

Copyright (C) 2017 by The American Association for Thoracic Surgery

https://doi.org/10.1016/j.jtcvs.2017.11.037
}

Type A acute aortic dissection is a common aortic emergency that has an exceedingly high mortality when left untreated. Even with surgical treatment, the early International Registry of Acute Aortic Dissections (IRAD) survival data revealed a hospital mortality of 349 of $1160(29.5 \%)$ for all type A dissections. ${ }^{1}$ Visceral malperfusion has long been recognized as an independent predictor of in-hospital mortality, despite central repair of type A dissection. ${ }^{2}$ Fortunately, IRAD has demonstrated that only about $3 \%$ of patients presenting with Type A aortic dissections have concomitant mesenteric ischemia. ${ }^{3}$ Similarly, an Italian registry described inferior results for patients with mesenteric ischemia despite timely repair of the central aortic dissection. ${ }^{4}$ This is unequivocal, and has been reported numerous times. It is therefore evident that a change in approach should be considered, addressing the malperfusion at the outset if possible. This has been well described by numerous authors, but probably best by the Michigan group. As early as 1997, Deeb and associates ${ }^{5}$ proposed an alternative pathway, performing fenestrations to restore visceral flow before central repair. Addressing the ischemia up front promoted improved survival in $88 \%$ of patients. In light of this evidence and further clinical experience, Patel and colleagues ${ }^{6}$ proposed an alternative algorithm that addressed the malperfusion syndrome first. In a further study by the Michigan group, ${ }^{7}$ a mortality of $17 \%$ from aortic rupture was observed while patients awaited resolution of their malperfusion syndrome under a protocol that specified distal repair first.

In this issue of the Journal, Lawton and coauthors ${ }^{8}$ have looked at an almost 20-year experience with type A dissection at an IRAD aortic center. The purpose of the study was to look at malperfusion, acidosis, and the combination of these as markers for mortality risk. There were a total of 282 type A dissections seen, with an operative mortality of $18 \%$. There were 80 cases of malperfusion, with a mortality of 80 of $282(28 \%)$, versus 22 of $202(11 \%)$ for those without malperfusion. There were 66 patients who had a base deficit of 5 or greater, with 24 of these having a base

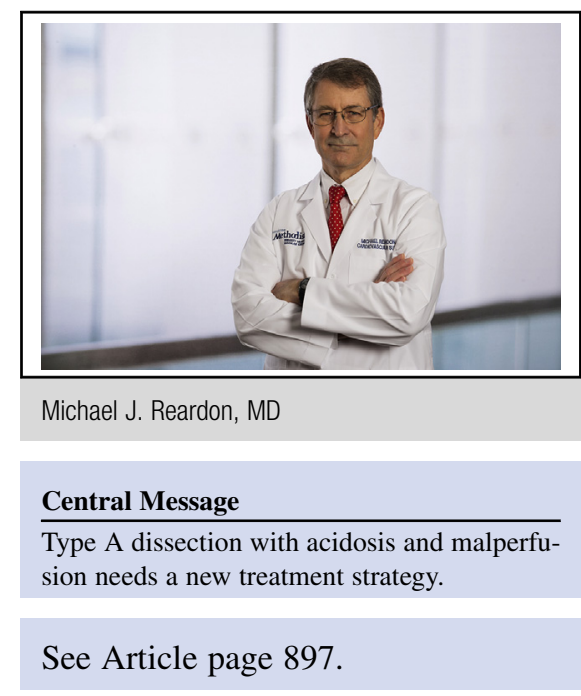

deficit of 10 or greater. For the 44 patients with a base deficit of 5 to 10 , the mortality was 11 of $42(26 \%)$; for those with a base deficit greater than 10, the mortality was 11 of 24 $(46 \%)$. Finally, they looked at the combination of acidosis and malperfusion, of which there were 21 cases. For malperfusion with a base deficit of 5 to 10 , the mortality was 10 of 21 (48\%); for malperfusion with a base deficit of greater than 10 , the mortality was 11 of 12 (92\%). Aortic surgeons already know most of this in broad terms, with Lawton and colleagues ${ }^{8}$ adding a more exact measure of the risks. This article points out the continued high mortality associated with type A dissection and better defines groups with an exceedingly high mortality.

For type A dissection with malperfusion or acidosis, the fundamental concept of tackling the malperfusion syndrome first by a less invasive and more prompt endovascular route raises a question: Why not extend that repair to the ascending aorta? The potential benefits of delaying the repair of a type $\mathrm{A}$ dissection to let the inflammatory cascade of mesenteric ischemia abate is contrasted by a persistent notable risk of rupture for those whose definitive aortic operation is delayed. In describing poor outcomes for patients with mesenteric ischemia in the setting of a type A dissection, Lawton and coauthors ${ }^{8}$ have better stressed something we already know. They conclude that an alternate algorithm should be entertained. In this age of high scrutiny for cardiac surgery outcomes, in which every death may be held against the surgeon, the question is what we do with this information. In the early days of repair of postmyocardial infarction ventricular septal defect it was found that waiting 6 weeks for the tissues to heal greatly improved the surgical mortality. Further study, however, showed that 
this was at the cost of losing $90 \%$ of the patients during this interval of healing. ${ }^{9}$ So in essence, what is the risk of avoiding risk? Is the solution to avoid surgery in these patients, who only account for about $3 \%$ to $4 \%$ of all patients with type A dissection, or should we simply restore perfusion to the gut and accept the ruptures that may occur during the interval between mesenteric recovery and definitive aortic repair? We thank Lawton and coworkers ${ }^{8}$ for bringing this information forward to the aortic community. Now the choice is ours to make: Do we take a step forward, or run from risk? We propose a step forward, with minimally invasive endovascular approaches being extended not only to restore the mesenteric insufficiency but also to repair the ascending aorta definitively by thoracic endovascular aortic repair.

\section{References}

1. Booher AM, Isselbacher EM, Nienaber CA, Trimarchi S, Evangelista A, Montgomery DG, et al; IRAD Investigators. The IRAD classification system for characterizing survival after aortic dissection. Am J Med. 2013;126:730. e19-24.

2. Leontyev S, Légaré JF, Borger MA, Buth KJ, Funkat AK, Gerhard J, et al. Creation of a scorecard to predict in-hospital death in patients undergoing op- erations for acute type A aortic dissection. Ann Thorac Surg. 2016;101: 1700-6.

3. Di Eusanio M, Trimarchi S, Patel HJ, Hutchison S, Suzuki T, Peterson MD, et al Clinical presentation, management, and short-term outcome of patients with type A acute dissection complicated by mesenteric malperfusion: observations from the International Registry of Acute Aortic Dissection. J Thorac Cardiovasc Surg. 2013;145:385-90.e1

4. Pacini D, Leone A, Belotti LM, Fortuna D, Gabbieri D, Zussa C, et al; RERIC (Emilia Romagna Cardiac Surgery Registry) Investigators. Acute type A aortic dissection: significance of multiorgan malperfusion. Eur J Cardiothorac Surg. 2013;43:820-6.

5. Deeb GM, Williams DM, Bolling SF, Quint LE, Monaghan H, Sievers J, et al. Surgical delay for acute type A dissection with malperfusion. Ann Thorac Surg. 1997; 64:1669-75; discussion 1675-7.

6. Patel HJ, Williams DM, Dasika NL, Suzuki Y, Deeb GM. Operative delay for peripheral malperfusion syndrome in acute type A aortic dissection: a longterm analysis. J Thorac Cardiovasc Surg. 2008;135:1288-95; discussion 1295-6.

7. Kamman AV, Yang B, Kim KM, Williams DM, Deeb GM, Patel HJ. Visceral malperfusion in aortic dissection: the Michigan experience. Semin Thorac Cardiovasc Surg. 2017;29:173-8.

8. Lawton JS, Moon MR, Liu J, Koerner DJ, Kulshrestha K, Damiano RJ Jr, et al. The profound impact of combined severe acidosis and malperfusion on operative mortality in the surgical treatment of type A aortic dissection. J Thorac Cardiovasc Surg. 2018;155:897-904.

9. Heitmiller R, Jacobs ML, Daggett WM. Surgical management of postinfarction ventricular septal rupture. Ann Thorac Surg. 1986;41:683-91. 